\title{
INFLUÊNCIA DO TEMPO DE SECAGEM, TAMANHO DAS PELOTAS, VAZÃO E TEMPERATURA DOS GASES NO PROCESSO DE SECAGEM DE PELOTAS DE MINÉRIO DE FERRO
}

\author{
Ana Caroliny Ferreira Pirola' \\ Daniel Ernesto Otárola Tasaico ' \\ Mauricio Cota Fonseca
}

\section{Resumo}

Este trabalho avaliou a influência do tamanho das pelotas, temperatura e vazão dos gases, e tempo de exposição na etapa de secagem de pelotas de minério de ferro, buscando determinar a contribuição individual e combinada das variáveis na eficiência deste processo. As variáveis respostas escolhidas para essa avaliação foram a perda de umidade e a resistência à compressão das pelotas cruas secas. Os resultados mostraram que as maiores perdas de umidade foram obtidas para as maiores temperaturas, vazão do gás e tempo de secagem. Não ocorreram diferenças significativas de perda de umidade em relação ao tamanho das pelotas. Os melhores resultados de resistência à compressão foram obtidos nas pelotas com tamanho entre $14,0 \mathrm{~mm}$ e $16,0 \mathrm{~mm}$, com os menores níveis de temperatura do gás e tempo de secagem. As vazões não apresentaram diferenças significativas em relação à resistência à compressão. Foi possível otimizar o experimento modificando os níveis dos fatores escolhidos de maneira a obter uma melhor eficiência na secagem, o que pode propiciar uma maior produtividade do forno de pelotização.

Palavras-chave: Secagem; Pelota de minério de ferro; Resistência à Compressão; Umidade.

\section{INFLUENCE OF GRANULOMETRY, FLOW, TEMPERATURE AND TIME IN THE DRYING PROCESS OF IRON ORE PELLETS}

\begin{abstract}
This study evaluate the influence of pellets size, gas temperature and flow, and exposing time on drying step of iron ore pellets, seeking to determine the individual and combined contribution of the variables in the efficiency of this process. The response variables used to assess the efficiency of drying were the moisture and the cold compression strength of dried pellets. The results showed that the higher pellet moisture loss rates were obtained for the highest temperature, gas flow and drying time. There were no significant differences moisture in relation the pellet size. The best results of cold compression strength were obtained to bigger pellets, lower gas temperature and drying time. Flow rates showed no significant differences in the cold compression strength. It was possible to optimize the experiment changing the levels of selected factors in order to obtain better efficiency in drying and higher pelletizing furnace productivity.
\end{abstract}

Keywords: Drying; Iron ore pellet; Cold compression strength; Moisture.

\section{INTRODUÇÃO}

O minério de ferro é a matéria-prima básica da siderurgia, respondendo pela carga metálica $(\mathrm{Fe})$ alimentada nos reatores de redução, como o alto forno e os módulos convencionais de redução direta. Processado nessas instalações, o minério dá origem ao ferro primário (ferro gusa no alto- forno e ferro esponja nos reatores de redução direta) que, após o devido tratamento nas aciarias, converte-se em aço.

O processo de beneficiamento do minério de ferro inicia-se na mina, onde o minério de interesse é lavrado. Se for necessária a adequação das propriedades químicas e

'Departamento de Engenharia Química, Universidade Vila Velha - UVV, Vila Velha, ES, Brasil. E-mail: carolinyfp@gmail.com

${ }^{2}$ Samarco Mineração, Anchieta, Brasil.

2176-1523 (C) 2019 Associação Brasileira de Metalurgia, Materiais e Mineração. Publicado pela ABM. Este é um artigo de acesso aberto distribuído sob os termos da licença Creative Commons CC BY-NC-ND (Attribution-NonCommercial-NoDerivs) - https:// creativecommons.org/licenses/by-nc-nd/4.0\%. 
físicas para atendimento ao mercado siderúrgico, o minério passa por uma rota de processo adequada, que pode ter uma etapa de concentração para a separação seletiva dos minerais [I].

Em algumas empresas de mineração, o itabirito lavrado é classificado, cominuído e concentrado até que apresente a especificação de um pellet feed. Este produto é transportado para a unidade de pelotização para ser aglomerado ou ser vendido como fino para o mercado transoceânico.

No processo de pelotização, o pellet feed, com granulometria inferior a $0,150 \mathrm{~mm}$ e com I I \% de umidade, é misturado com quantidades pré-definidas de aglomerante orgânico ou inorgânico, calcário e carvão mineral ou coque. Esta mistura é aglomerada em discos de pelotização, que operam com um determinado ângulo de inclinação e uma determinada velocidade de rotação. Ao rolar dentro do disco ocorre a formação do aglomerado esférico chamado de pelota crua úmida [2].

Dentre as etapas subsequentes ao pelotamento, 0 processo de secagem das pelotas de minério de ferro no forno de pelotização é um dos mais importantes para que estas tenham uma resistência mínima exigida na etapa de queima. As pelotas devem perder a água e preservar a sua integridade física, resistindo às tensões internas que surgem em função da evaporação da água contida nos poros e às pressões dinâmica e estática dos gases quentes do forno [3].

Para que as pelotas, após passar pelos fornos de pelotização, possam resistir às operações de manuseio e transporte marítimo até o cliente e para que suportem os choques térmicos e as pressões no interior dos reatores de redução, é necessário submetê-las a um tratamento térmico (processo de endurecimento das pelotas) cuidadoso, bem balanceado e eficiente para que se garanta uma resistência física e mecânica apropriada [4].
Tradicionalmente, a qualidade física das pelotas de minério de ferro é obtida através do processamento térmico das pelotas em fornos do tipo Grelha Móvel (Straight Grate), figura I, apesar de existirem outras tecnologias no mercado. Os fornos de endurecimento processam as pelotas em quatro principais etapas sequenciais: secagem, pré-queima, queima e resfriamento [3].

Segundo Meyer [6], todas as propriedades dos aglomerados são obtidas durante o processo de endurecimento, sendo esta etapa, portanto, decisiva para garantir a qualidade da pelota.

Mediante os fatores apresentados, considerou-se pertinente selecionar para estudo as principais variáveis do processo de secagem de pelotas de minério de ferro, que são: tamanho das pelotas, vazão e temperatura dos gases, e o tempo, avaliando a influência individual de cada variável, bem como a interação entre elas, na eficiência deste processo. Assim, o presente estudo buscou definir as melhores condições para aumentar a eficiência do processo.

\section{MATERIAIS E MÉTODOS}

\section{I Preparação da Mistura e Produção das Pelotas Cruas em Disco de Pelotamento Piloto}

$\mathrm{Na}$ etapa de pelotização, o pellet feed é previamente moído até adquirir as características demandadas de granulometria na fração menor do que $44 \mu \mathrm{m}$ ( $88 \%$ mínimo) e área superficial específica de $1650 \mathrm{~cm}^{2} \cdot g^{-1}$ mínima. Este minério de ferro moído recebe a adição de insumos essenciais para garantir a qualidade das pelotas produzidas, em relação as suas características físicas, químicas e metalúrgicas

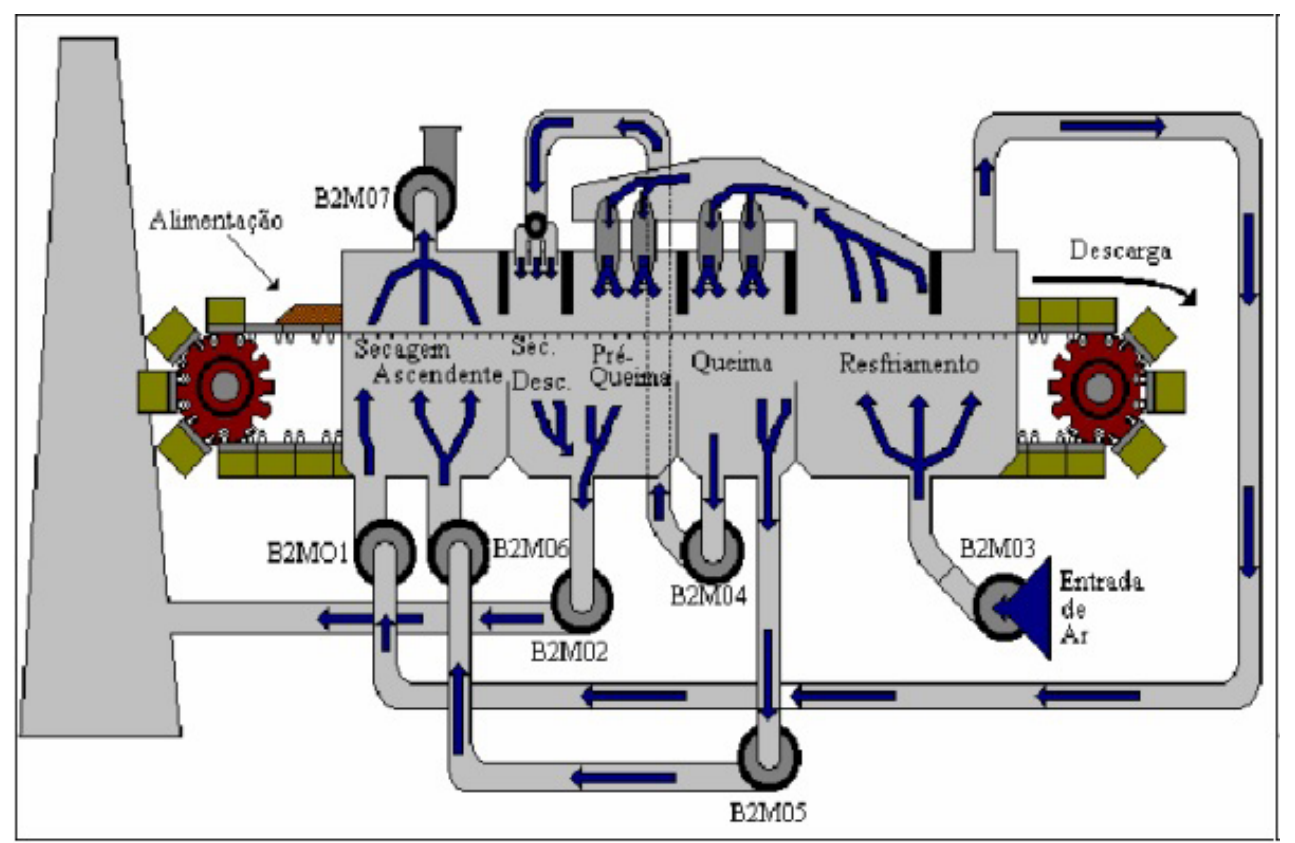

Figura I. Forno de pelotização do tipo grelha móvel [5]. 
necessárias à sua utilização nos processos subsequentes [2]. As caracterizações físico-químicas do pellet feed e dos insumos podem ser vistas na tabela $I$.

A dosagem de carvão objetivou $1 \%$ de carbono na mistura, a de calcário objetivou uma basicidade binária de 0,60 e a de aglomerante orgânico padrão de 0,035\% em relação à massa de minério.

As misturas de pellet feed com os insumos (calcário, carvão e aglomerante orgânico) foram preparadas em um misturador piloto da marca Eirich, modelo R-08W. A mistura, devidamente preparada, foi alimentada em um disco de pelotamento em escala piloto com um diâmetro de I metro e a profundidade útil da panela de $20 \mathrm{~cm}$, onde foram produzidas as pelotas cruas úmidas do tipo Redução Direta, que foram utilizadas nos testes realizados.

\subsection{Análise das Propriedades das Pelotas Cruas}

\subsection{Distribuição granulométrica das pelotas cruas}

Após a etapa de aglomeração, as pelotas cruas foram classificadas em peneiras com malhas de $16,0 \mathrm{~mm}, 14,0 \mathrm{~mm}$, $12,5 \mathrm{~mm}$ e $9,5 \mathrm{~mm}$. As pelotas foram classificadas como pelotas de faixa menor, com tamanho entre 9,5 e $12,5 \mathrm{~mm}$, e como pelotas de faixa maior, com tamanho entre 14,0 e $16,0 \mathrm{~mm}$. Os tamanhos das pelotas utilizadas nos testes seguiu norma padrão adotada por uma determinada empresa de mineração.

\subsubsection{Qualidade física das pelotas cruas}

Foi avaliado se as pelotas cruas possuíam resistência suficiente para suportar as etapas subsequentes do processo.

Estão apresentadas na tabela 2 as faixas de valores de referência que são considerados adequados para os parâmetros de qualidade das pelotas cruas do tipo Redução Direta (RD).

\subsubsection{Teste de resistência à compressão das pelotas cruas}

O teste de resistência à compressão é realizado em pelotas úmidas e secas com a finalidade de conhecer a resistência do aglomerado à aplicação de uma carga contínua sobre ele. As pelotas não devem sofrer quebras até serem alimentadas na grelha móvel.

No teste foi utilizada uma prensa manual no qual 10 pelotas sem trincas, para cada faixa de tamanho, foram submetidas à ação de uma força compressiva uniaxial. Este ensaio consiste em colocar uma pelota entre duas placas paralelas e comprimi-la, até que ocorra a sua ruptura [I].

\subsubsection{Teste de resistência a quedas (“drop test”)}

Este ensaio tem como objetivo simular a resistência das pelotas cruas às diversas quedas que elas sofrem do disco de pelotamento até a grelha $[\mathrm{I}]$. As pelotas utilizadas

Tabela I. Caracterizações físico-químicas do pellet feed e dos insumos

\begin{tabular}{cccc}
\hline Descrição & Pellet Feed & Calcário & Antracito \\
\hline & Análise Química (\%) & & 4,40 \\
\hline $\mathrm{Fe}$ & 67,49 & -- & 45,57 \\
$\mathrm{SiO}_{2}$ & 1,02 & 2,91 & 29,67 \\
$\mathrm{Al}_{2}$ & 0,30 & -- & 6,07 \\
$\mathrm{CaO}$ & 0,08 & 47,20 & 2,06 \\
$\mathrm{MgO}$ & 0,02 & 3,33 & -- \\
$\mathrm{PPC}$ & 1,95 & 44,60 & 73,04 \\
Carbono Fixo & -- & -- & 10,57 \\
Matérias Voláteis & -- & -- & 16,39 \\
Cinzas & -- & -- & $($ Continuação) \\
& & & 6762 \\
\hline Poder Calorífico $(\mathrm{cal} / \mathrm{g})$ & -- & -- & 52,0 \\
\hline Área Superficial Específica $(\mathrm{cm} / \mathrm{g})$ & Análise Granulométrica (\%) & & 6061 \\
\hline
\end{tabular}

Tabela 2. Parâmetros de qualidade para pelota crua [7]

\begin{tabular}{cc}
\hline Parâmetros & Valores de Referência para Pelotas RD \\
\hline Diâmetro Médio $(\mathrm{mm})$ & $9,5-12,5$ \\
& $14,0-16,0$ \\
Resistência à compressão da pelota crua úmida (kgf/pelota) & $>1,5$ \\
Resistência à compressão da pelota crua seca (kgf/pelota) & $>3,0$ \\
\hline
\end{tabular}


Tabela 3. Planejamento do Experimento

\begin{tabular}{|c|c|c|c|}
\hline Granulometria & Vazão $\left(\mathrm{Nm}^{3} / \mathrm{h}\right)$ & Tempo (min) & Temperatura $\left({ }^{\circ} \mathrm{C}\right)$ \\
\hline Faixa Menor & 11,10 & 2,0 & 300 \\
\hline \multirow[t]{5}{*}{ (Entre 9,5 e $12,5 \mathrm{~mm}$ ) } & & 2,5 & 350 \\
\hline & & & 400 \\
\hline & $|4,8|$ & 2,0 & 300 \\
\hline & & 2,5 & 350 \\
\hline & & & 400 \\
\hline Faixa Maior & 11,10 & 2,0 & 300 \\
\hline \multirow[t]{5}{*}{ (Entre 14,0 e $16,0 \mathrm{~mm}$ ) } & & 2,5 & 350 \\
\hline & & & 400 \\
\hline & $|4,8|$ & 2,0 & 300 \\
\hline & & 2,5 & 350 \\
\hline & & & 400 \\
\hline
\end{tabular}

para realização do teste de resistência às quedas foram as pelotas cruas úmidas selecionadas com granulometria entre 9,5 e $12,5 \mathrm{~mm}$ e entre 14,0 e $16,0 \mathrm{~mm}$.

No teste, 10 pelotas de cada amostra, sem trincas, foram submetidas ao ensaio de quedas. Cada pelota foi solta, individualmente, de uma altura de $45 \mathrm{~cm}$, várias vezes, até que a mesma apresentasse alguma trinca. A média do número de quedas que a pelota suportou sem apresentar trincas foi o valor da sua resistência a quedas. São consideradas pelotas com boa resistência as que suportam de 5 a 8 quedas.

\subsubsection{Umidade das pelotas cruas}

Para a determinação da perda de umidade das pelotas na etapa de secagem, foram pesados, para cada teste, $1,97 \mathrm{~kg}$ de pelotas que foram colocadas em um equipamento piloto utilizado para realizar a secagem das mesmas, chamado de Secador de Pelotas. Logo após, os aglomerados foram retirados do equipamento e pesados novamente para conhecer a massa da pelota crua seca. Após a saída do secador e pesagem das pelotas, as amostras foram colocadas em estufa à $100^{\circ} \mathrm{C}$ por duas horas para verificar se as pelotas continuavam perdendo umidade, e consequentemente obter a certeza da eficiência da secagem feita no Secador de Pelotas.

A porcentagem da perda de umidade das pelotas cruas foi calculada através da equação $I$.

$$
\text { Umidade }=\left(\left[\left(P_{-} u-P_{-} s\right) \times 100\right]\right) / P_{-} u
$$

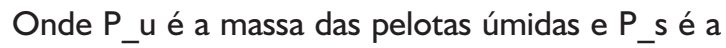
massa das pelotas secas.

\subsection{Secagem de Pelotas de Minério de Ferro no "Secador de Pelotas"}

A secagem das pelotas de minério de ferro foi realizada em um equipamento piloto desenvolvido especificamente para este fim, chamado de Secador de Pelotas.

Após passarem pela classificação granulométrica e pelos testes de avaliação da qualidade física, as pelotas, devidamente pesadas, foram colocadas no Secador de Pelotas para realização da etapa de secagem. Após a realização desta etapa, as pelotas foram pesadas novamente e através das massas das pelotas úmidas e secas foi possível determinar a porcentagem de perda de umidade. Em seguida, foram realizados testes de resistência à compressão com as pelotas secas para a determinação da sua resistência à compressão.

As condições de secagem foram estabelecidas de acordo com as condições operacionais adotadas no processo industrial. O planejamento de experimentos foi elaborado no software estatístico Minitab, e está apresentado na tabela 3.

\section{RESULTADOS E DISCUSSÕES}

\section{I Análises dos Resultados da Etapa de Pelotamento}

As propriedades das pelotas cruas úmidas produzidas, avaliadas na etapa de pelotamento, foram: a resistência à compressão e a resistência à queda (Drop Test).

\section{I.I Resistência das pelotas cruas úmidas}

Os resultados obtidos nos ensaios realizados mostraram que as pelotas da faixa de tamanho entre 14,0 e $16,0 \mathrm{~mm}$ apresentaram uma média de resistência à compressão das pelotas cruas úmidas de $1,98 \pm 0,34 \mathrm{kgf} /$ pelota, maior do que a média da resistência das pelotas da faixa de tamanho entre 9,5 e 12,5mm, que apresentaram uma resistência de I, I7 0, I $9 \mathrm{kgf} /$ pelota. Pode-se entender este resultado analisando a equação 2 que é utilizada para o cálculo da força de compressão da pelota, e o diâmetro é uma das variáveis.

$$
\mathrm{F}=\mathrm{K} \sigma_{-} \mathrm{T}^{\wedge} \mathrm{D}^{2}
$$

Segundo Newitt; Conway-Jones*, K é a constante de proporcionalidade, $\mathrm{F}$ é a carga aplicada, $\mathrm{D}$ é o diâmetro da esfera e $\sigma_{-} T$ é a tensão de ruptura. $O$ valor de $\sigma_{-} T$ é característico para cada tipo de material empregado na aglomeração. Referindo-se a pelotas de minério de ferro, 
que normalmente usam o mesmo ligante e cujas dosagens variam muito pouco, pode-se considerar este constante [I]. Através da equação 2 entende-se que aumentando o diâmetro do aglomerado, aumenta-se a força de compressão da pelota.

*Newitt, D.M., Conway-Jones, J.M. - A contribution to the theory and practice of granulation - Transactions of Institution of Chemistry Engineering, 36 - 1958, p. 422 - 442 apud [2]

\section{I.2 Resistência a quedas (Drop Test)}

Nos ensaios realizados, as pelotas da faixa maior apresentaram uma média de resistência à queda de 5,4 quedas, enquanto que as pelotas de faixa menor apresentaram uma média de 7,7 quedas. Logo, as pelotas, em ambas as faixas de tamanho, apresentaram boa resistência, pois pelotas que suportam de 5 a 8 quedas são consideradas adequadas ao processo.

\subsection{Análise Específica dos Resultados da Etapa de Secagem}

Para avaliação do processo de secagem, as seguintes variáveis respostas foram consideradas: perda percentual de umidade e resistência à compressão da pelota crua seca. A análise de ambas as variáveis é importante, pois é necessário que se obtenha uma taxa elevada de secagem e o aglomerado apresente boa resistência à compressão.

\subsection{Interações entre os fatores estudados e os efeitos causados na perda de umidade}

A figura 2 mostra a interação dos fatores estudados e o efeito na variável resposta perda de umidade.

Observou-se nos resultados que não houve diferenças significativas de perda de umidade em relação ao diâmetro das pelotas.

Notou-se que quanto maior a temperatura dos gases, maior foi a perda de umidade para quaisquer faixas de tamanho das pelotas, vazão dos gases e tempo de secagem. A média de aumento na eficiência de secagem foi de 10 pontos percentuais para o aumento da temperatura de $300^{\circ}$ para $400^{\circ} \mathrm{C}$.

A vazão dos gases também é determinante para o aumento da eficiência da secagem. Na operação, frequentemente aumenta-se a velocidade da grelha, ou seja, aumenta-se a massa de pelotas que passam pelas diversas regiões do forno, e nem sempre ocorre um aumento no fluxo de gases na mesma proporção. A combinação da vazão de gases e alta temperatura elevou a eficiência de remoção da água nas pelotas. Vale ressaltar que a decisão de trabalhar com temperatura ou vazão elevada será determinada pelas restrições de condições operacionais dos ventiladores e dos queimadores de gás do forno. Este resultado foi explicado, segundo Pereira e Seshadri [8], pois elevadas vazões de gases quentes e temperaturas mais elevadas dos gases, aumentam a eficiência da secagem.

Quanto ao tempo, a necessidade de maximizar a produção aumentando a velocidade da grelha reduz cada

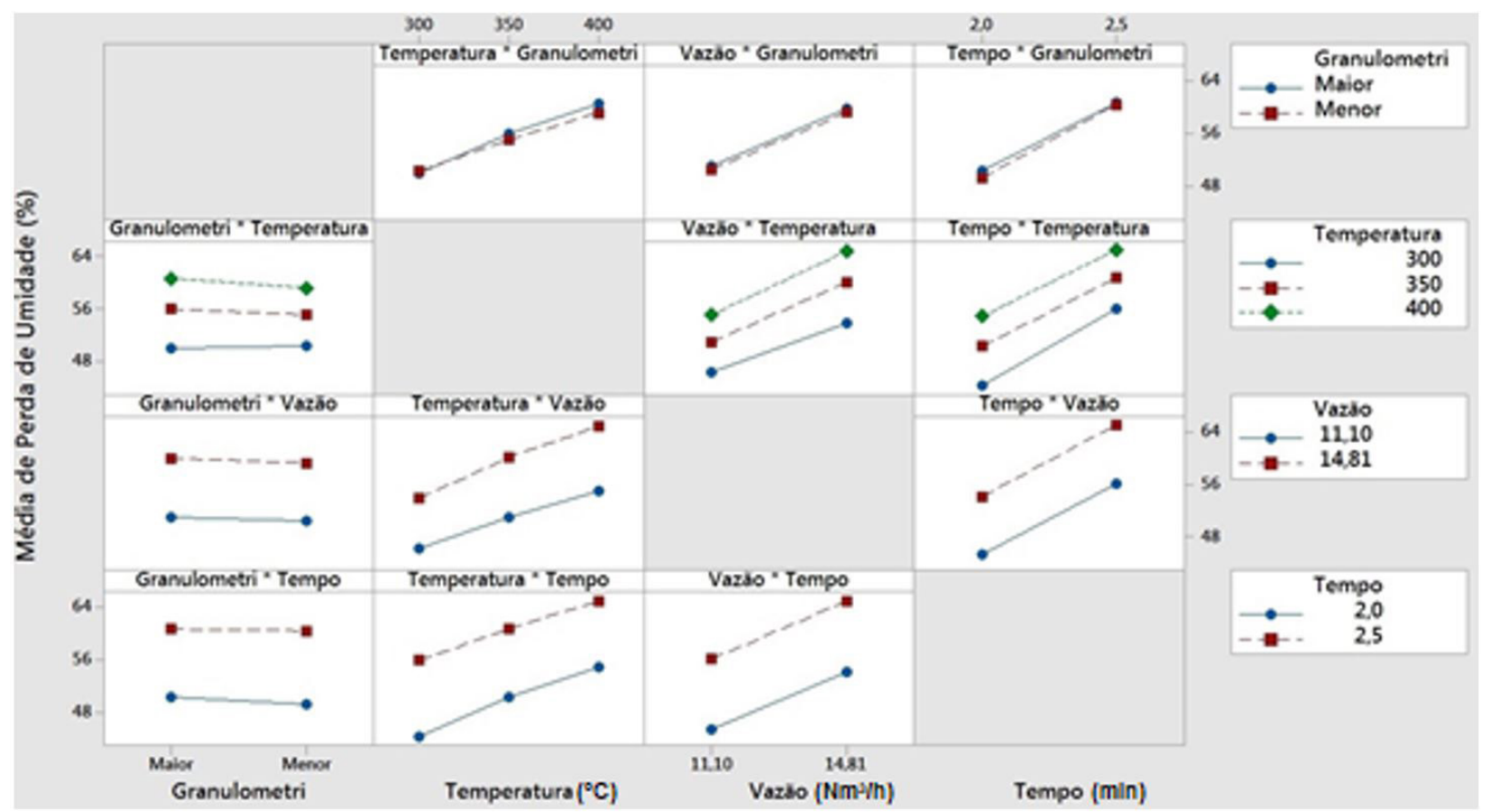

Figura 2. Interação para perda de umidade (\%). 
vez mais o tempo das pelotas nas diversas regiões do forno. Entretanto, tempos maiores levaram a resultados melhores de secagem independente da temperatura, granulometria e vazão de gases quentes.

\subsubsection{Interações entre os fatores estudados e os efeitos causados na resistência à compressão da pelota crua seca}

A figura 3 mostra a interação dos fatores estudados e o efeito na variável resposta resistência à compressão das pelotas cruas secas.

Através dos resultados da figura 3, observou-se que as pelotas de faixa maior mostraram maior resistência à compressão em relação aos demais fatores estudados. Este resultado foi explicado segundo Fonseca [I], pois quanto maior o tamanho das pelotas, maior a força necessária para sua ruptura destrutiva em um ensaio de compressão.

Notou-se que quanto maior a temperatura dos gases, menor foi a resistência à compressão das pelotas cruas secas para quaisquer níveis de vazão dos gases, faixa de tamanho das pelotas e tempo de secagem. A média de perda de resistência à compressão foi de aproximadamente I,0 kgf/pelota para o aumento da temperatura de $300^{\circ} \mathrm{C}$ para $400^{\circ} \mathrm{C}$.

Observou-se que não houve diferenças significativas na média de resistência à compressão das pelotas cruas secas em relação às vazões dos gases.

Quanto ao tempo, o raciocínio foi o mesmo utilizado para a umidade. A necessidade de maximizar a produção diminui cada vez mais o tempo das pelotas nas diversas regiões do forno. Uma tendência natural é que quanto maior o tempo de secagem, para uma mesma temperatura e vazão, melhor seja a resistência final do aglomerado. Entretanto, os resultados do experimento mostraram uma tendência contrária, pois quanto mais tempo as pelotas permaneceram na zona de secagem, maior foi a perda de resistência das pelotas para quaisquer níveis de temperatura, vazão e granulometria. A explicação pode estar no fato que as pelotas, após o ensaio de secagem no Secador de Pelotas, foram levadas para uma estufa a $100^{\circ} \mathrm{C}$ com a finalidade de observar se as amostras continuariam perdendo umidade e consequentemente se obter a certeza da eficiência do equipamento piloto. Logo, a utilização de tempos menores levou a uma umidade residual maior na pelota. Desta forma o mecanismo de secagem foi mais suave, levando a maior resistência do aglomerado.

\subsubsection{Análise geral dos resultados da etapa de secagem}

A tabela 4 mostra os resultados obtidos para a perda de umidade e para a resistência à compressão das pelotas cruas secas de ambas as faixas de granulometria das pelotas. Os objetivos foram aumentar a produtividade do processo e maximizar a perda de umidade sem perder resistência física e sem degradar o aglomerado. Percebeu-se que uma propriedade foi contrária a outra. Ao propiciar uma secagem mais rápida através de maiores

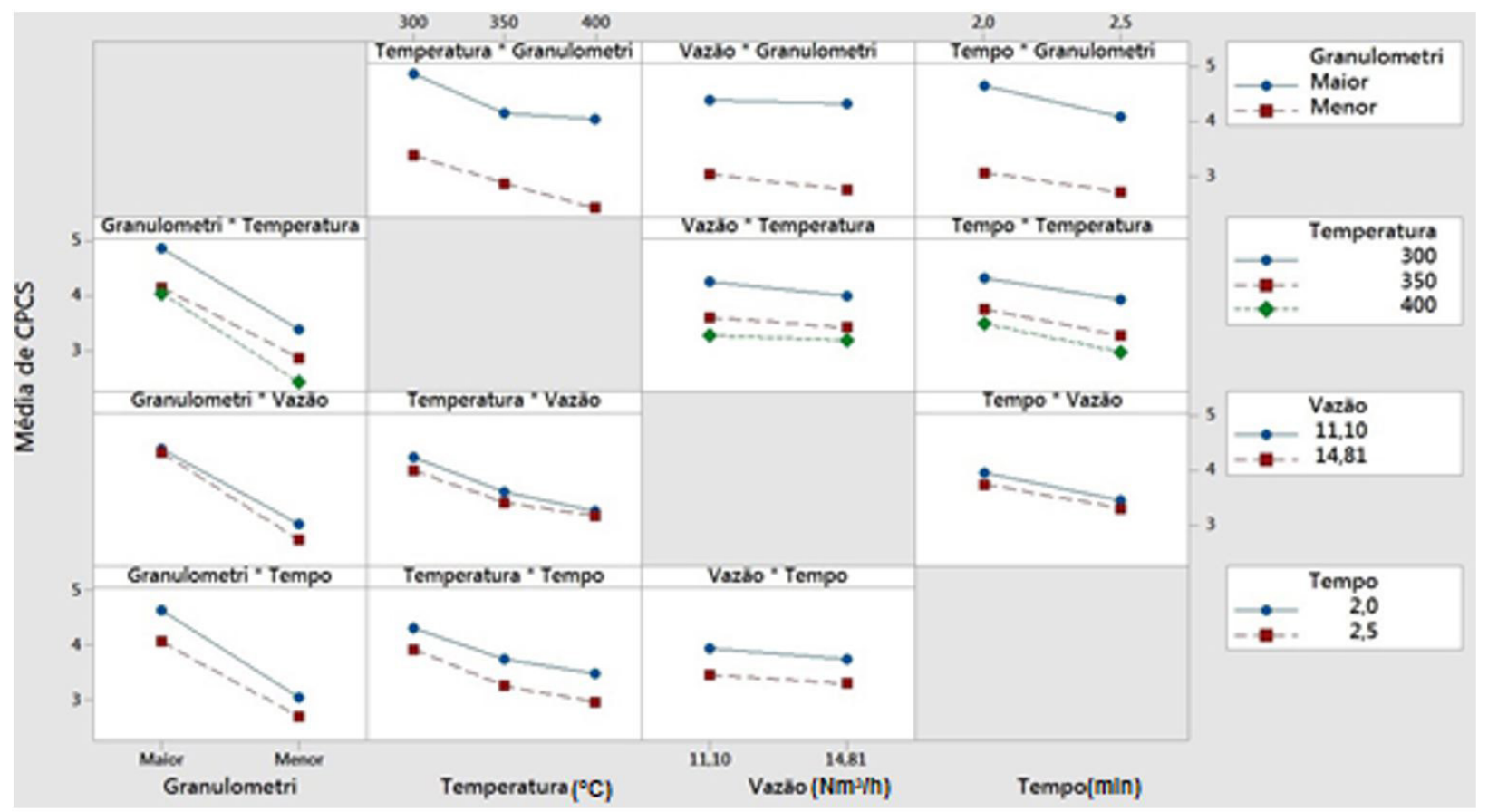

Figura 3. Interação para resistência à compressão das pelotas cruas secas. 
vazões e maiores temperaturas, o aglomerado apresentou resistência menor.

Para contornar esta situação, o ideal foi otimizar o processo de maneira a maximizar a produtividade (menores tempos), ajustando o fluxo gasoso e a temperatura.

\subsection{Determinação da Melhor Condição de Secagem}

Utilizando o software estatístico Minitab, simulou-se algumas situações de otimização do processo realizada utilizando como dados a variação do tamanho das pelotas, o tempo de secagem do aglomerado, e temperatura e vazão dos gases.
A primeira situação foi maximizar a perda de umidade e a resistência à compressão da pelota crua seca, simulando uma produção anual de 6 milhões de toneladas métricas secas de pelotas, como pode ser visualizado na figura 4.

De acordo com a simulação, a condição ótima seria elevada temperatura $\left(400^{\circ} \mathrm{C}\right)$, maior vazão, pelotas maiores e menor velocidade da grelha. As respostas seriam uma perda de 72,01\% da umidade e uma resistência à compressão das pelotas cruas secas na ordem de 3,75 kgf/pelota.

A figura 5 mostrou o resultado quando se procurou maximizar a produtividade, simulando uma produção anual de 7,5 milhões de toneladas métricas secas.

Tabela 4. Resumo dos resultados obtidos através dos testes realizados

\begin{tabular}{ccc}
\hline Fatores & $\begin{array}{c}\text { Eficiência de } \\
\text { Secagem }\end{array}$ & $\begin{array}{c}\text { Resistência à compressão } \\
\text { das pelotas cruas secas }\end{array}$ \\
\hline Temperatura & Aumentou & Diminuiu \\
Vazão & Aumentou & Diminuiu \\
Tempo & Aumentou & Diminuiu \\
\hline
\end{tabular}

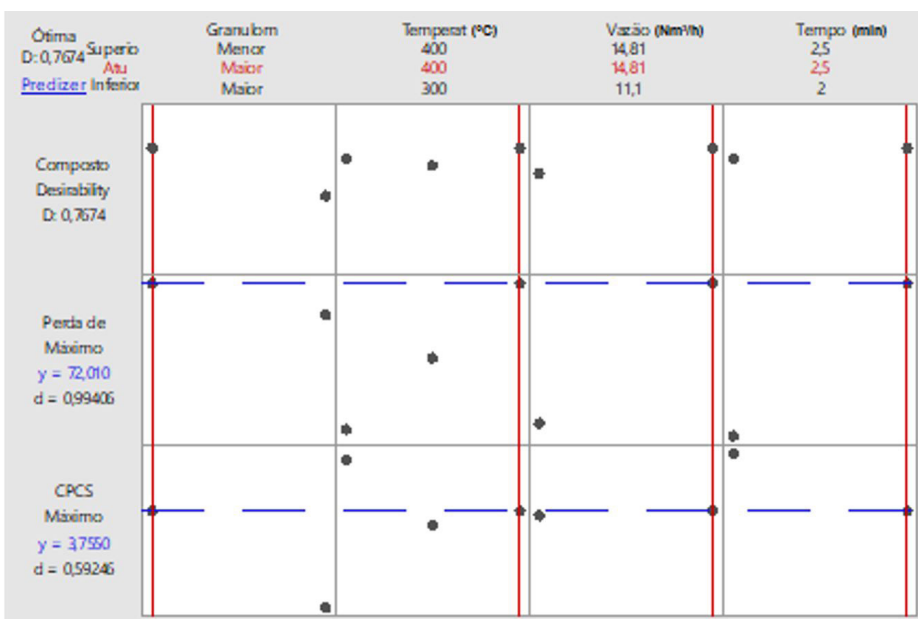

Figura 4. Maximização da perda de umidade e da resistência à compressão das pelotas secas.

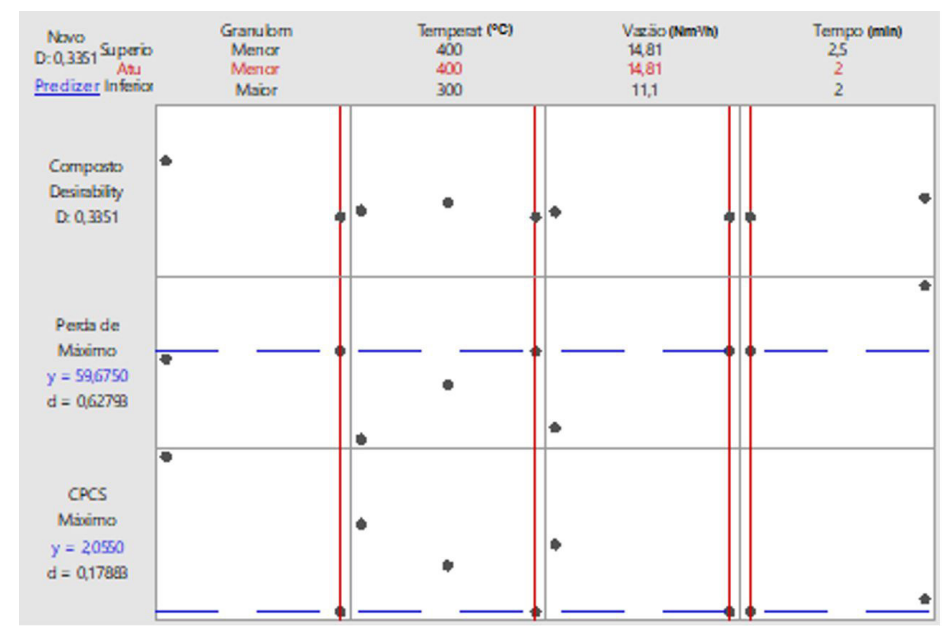

Figura 5. Maximização da produtividade. 
O resultado foi uma queda na eficiência da perda da umidade e da resistência à compressão, que anteriormente era de $72,01 \%$ e $3,75 \mathrm{kgf} /$ pelota e com a aceleração da grelha resultou em $58,45 \%$ e $2,05 \mathrm{kgf} /$ pelota, respectivamente.

\section{CONCLUSÕES}

De acordo com os resultados obtidos concluiu-se que uma elevada temperatura do gás aumentou a eficiência da secagem, porém, nesta condição, as pelotas apresentaram uma menor resistência física.

Em relação à qualidade das pelotas cruas úmidas e secas, relacionando os resultados dos testes de resistência à compressão com a tabela 2, foi possível concluir que as pelotas cruas úmidas e secas, de faixa maior, foram consideradas de boa qualidade, já que apresentaram resistência maior que I,5kg/pelota para pelotas cruas úmidas, e resistência maior que 3,0kgf/pelota para pelotas cruas secas. O tamanho das pelotas não influenciou significativamente na perda de umidade, mas houve grande influência em relação à resistência à compressão das pelotas cruas secas, já que as pelotas de faixa maior apresentaram melhor resistência à compressão quando comparadas às pelotas de faixa menor. Este resultado justifica-se através da equação 2 que demonstrou que aumentando o diâmetro do aglomerado, aumenta-se a força de compressão da pelota.

A elevada vazão do gás aumentou a perda percentual de umidade das pelotas, mas não influenciou significativamente na resistência à compressão das pelotas cruas secas.

As pelotas apresentaram maior perda percentual de umidade quando permaneceram mais tempo na etapa de secagem, porém, nesta condição, o aglomerado perdeu resistência física.

A maximização da perda percentual de umidade e da resistência à compressão das pelotas cruas secas ocorreu em maiores níveis de temperatura e vazão, pelotas de faixa granulométrica maior, e menor velocidade da grelha. A maximização da produtividade ocorreu em pelotas menores, temperatura e vazão elevadas e maior velocidade da grelha. Logo, de acordo com os resultados, foi possível concluir que para que haja um equilíbrio entre a maximização da perda percentual de umidade e da resistência à compressão, e a produtividade, será necessária a realização de testes futuros.

\section{REFERÊNCIAS}

I Fonseca MC. Influência da distribuição granulométrica do pellet feed no processo de aglomeração e na qualidade da pelota de minério de ferro para redução direta [dissertação]. Ouro Preto: Universidade Federal de Ouro Preto; 2004.

2 França SCA, Luz AB, Sampaio JA. Tratamento de minérios. 5. ed. Rio de Janeiro: CETEM/MCT; 2010.

3 Athayde M. Modelamento fluidodinâmico da zona de queima de fornos de grelha móvel para pelotização de minério de ferro [dissertação]. Belo Horizonte: Universidade Federal de Minas Gerais; 2013.

4 Fonseca VO. Envelhecimento de pelotas de minério de ferro com diferentes basicidades e teores de $\mathrm{MgO}$ [dissertação]. Ouro Preto: Universidade Federal de Ouro Preto; 2002.

5 Matos AP. Influência da temperatura, pressão, produção e granulometria no processo de secagem das pelotas cruas [dissertação]. Ouro Preto: Universidade Federal de Ouro Preto; 2007.

6. Meyer K. Pelletizing of iron ores. Heidelberg: Springer-Verlag Berlin, Dusseldorf: Verlag Stahleisen mbH, s.n., 1980.

7 Souza AL. Efeito da adição de cal hidratada na etapa de aglomeração das pelotas de minério de ferro produzidas pela Samarco S.A. [Dissertação]. Belo Horizonte: Universidade Federal de Minas Gerais; 2014.

8 Pereira R O S, Seshadri V. Secagem de pelotas de minério de ferro. Metalurgia - ABM. I985;4I(328): I4I-I44.

Recebido em: 05 Jul. 2017

Aceito em: 10 Mai. 2018 